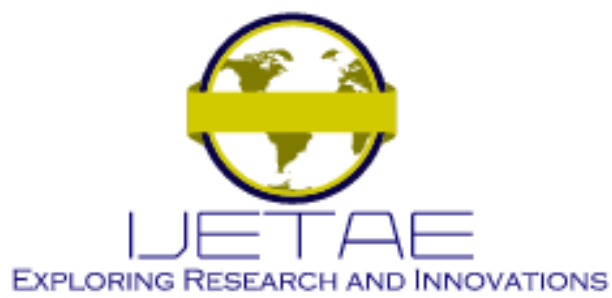

International Journal of Emerging Technology and Advanced Engineering

Website: www.ijetae.com (E-ISSN 2250-2459, Scopus Indexed, ISO 9001:2008 Certified Journal, Volume 11, Issue 06, June 2021)

Manuscript Received: 23 April 2021, Received in Revised form: 29 May 2021, Accepted: 08 June 2021

DOI: 10.46338/ijetae0621_09

\title{
Interactive Recommender System for Identifying Learning Partner
}

\author{
Tanty Oktavia ${ }^{1}$, Surya Sujarwo ${ }^{2}$ \\ ${ }^{1}$ Information Systems Department, School of Information Systems, Bina Nusantara University, Jakarta, Indonesia 11530 \\ ${ }^{2}$ Computer Science Department, School of Computer Science, Bina Nusantara University, Jakarta, Indonesia 11530
}

\begin{abstract}
Currently, higher education must open their mindset to change the learning process. This process cannot still stay on a conventional process that only involved students and lecturers as learning participants because to capture what the current industry needs and the trend of knowledge, higher education institutions must collaborate with external parties as learning partners to give a global perspective about the industrial needs and trends. The process to identify a learning partner to contribute to the learning process is not easy way. The higher education institution must select which partner has appropriate skills and competency suitable for the subject's course. Many parameters will be involved in the selection process to identify the right partner. In this proposed system, external parties in this context consist of professionals or educators from the external institution easily can be defined to be selected as learning partners based on their competency and experience, that listed on social media LinkedIn as a professional platform. The method to build this interactive recommender system in this study is based on design science research that identifies step by step design stage to propose the best way solution for the recommender system. The result of this study is an interactive recommender system that can help higher education to find out the best candidate for their learning partner so the collaboration of learning can be implemented effectively.
\end{abstract}

Keywords - recommender, design science research, learning partner, interactive recommender system.

\section{INTRODUCTION}

Today, the internet contains a huge amount of information, which must then can be filtered to determine suitable facts for certain objectives [1]. With the expansion of online applications that using the internet as a mediator, many organizations so dramatically try to implement innovation that can read the pattern of transaction that has become difficult for an organization to analyse manually [2]. The intense growth of the internet drives recommender systems has been implemented to a variety of line systems, such as Amazon, Facebook, Globo, YouTube, Netflix, Last.FM, etc [3].
Therefore, there are many increasing the connectivity to various recommender systems that can fulfill the organization's concern [4]. Recommender systems play a key role today as a system that offers personalized suggestions [5]. This system is a prominent area within artificial intelligence, which can predict items based on user preferences, so this implementation can impact to increase business performance [6]. This condition also affects higher education institutions as a centre of excellence in every process. They must be aware of how to deliver service excellence to their stakeholders. One important factor for education institutions to keep sustain to deliver education is they must make sure the curriculum complies with the industry expectation, so the graduates can compete with others from the different or same university.

There are many concerns from the higher education institution sides when their students in the last term and ready to enter working life as an employee in the company, some concern of that are "can they catch up with work environment? Are the graduate's knowledge and skill match with the company needs? Can they compete with the other graduates from the different university" these thoughts could be the problem if there are many gaps happened, such as the gap between graduate's competency and company expectation, this condition will drag on the negative impact to the university value as a place to educate a student with the current knowledge skill. Therefore, many higher education institutions decide to level up their standard and they open their mind to involve an external partner from companies and external universities as a learning partner to give feedback about current competency requirements for graduation in the industry, so it will drive universities to innovate how to prepare their graduate to be ready catch up with the current industry needs. 


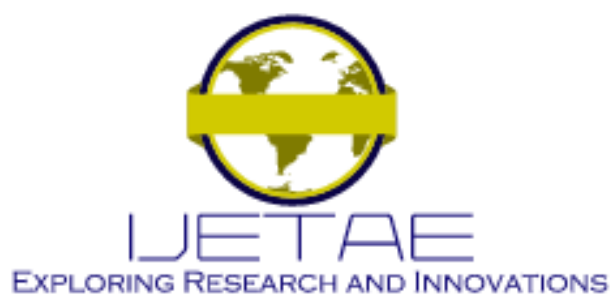

International Journal of Emerging Technology and Advanced Engineering

Website: www.ijetae.com (E-ISSN 2250-2459, Scopus Indexed, ISO 9001:2008 Certified Journal, Volume 11, Issue 06, June 2021)

The initiation of this problem push organization to modify their learning strategy. Nadiem Makarin, as minister of education and culture of the Republic of Indonesia also initiates to open our learning environment more attractive, so students can learn from multichannel not only from one side. Many pieces of knowledge and practical experience from external parties will enrich student competency. According to this situation, higher education institution tries to combine many system solutions to accommodate the best system support to realize this expectation. In this era, the recommender system is a very powerful tool today because this system has the capability of filtering the information according to the rule or user interest and provide the best suggestion [7]. One of the main drawbacks of the recommender system that they only deal with a single domain. Meanwhile, real-world domains could be related to others by some common situation [7]. In this study, the recommender system could be the one solution that can bring innovation to the higher education institution, because there are many recommender systems implementations success to support many sectors, such as movie/music recommendation, match-making companies, clothing industry, etc. They could provide suggestions to users that suitable for their needs and preferences[8]. Many of these recommendation systems rely on historical data, such as the purchase activity, user behavior, etc. that compiled using many techniques to define many options. The method of most recommendation systems is based on a clustering algorithm to recommend several options. Otherwise, there is still limited research in recommender systems that can identify learning partners in the learning process for a higher education institution. According to this gap, this study will focus on creating recommender systems that can support higher education institutions.

In this case, the recommender system will have a role as an intermediary system to matchmaking between learning partners and the subject's course. The recommender system must recommend learning partners that suitable for the subject's course based on learning partners' competency, skill, and experience. The functionality system act as a screening process that helps higher education get a snapshot of learning partner profile from social media, that in this study use LinkedIn as a provider to search learning partners candidate because this media can explore based on job title, skills, endorsement, degree as the searching keywords rather than using job search type.
Without such a screening process using social media, higher education institutions will be extremely difficult to identify the learning partner which relevant to the subject's course. This recommender system also could potentially reduce unsuitable partners join in the learning process because to identify the candidate, the university has to define the parameter as criteria to search. To overcome some difficulties faces by a higher education institution to select learning partners, interactive recommender systems have emerged as an effective tool in partner screening and filtering. With the generalization requirement from a higher education institution in Indonesia perspective, this study will result in an interactive recommender system that includes its design and experiment to improve the use of data intelligence to provide better support for collaborative learning.

\section{THEORETICAL BACKGROUND}

As a foundation of research background, this study refers to some literature that supports theoretical of the object of research, which consists of:

\subsection{Recommender System}

Recommender systems use a class of information filter systems, that have the main goal to provide personalized recommendations, services, content to users [9]. The functionality of recommender systems focuses on information filter tools that aid users in their information access, through prediction and recommendations from history data patterns [10]. Based on the literature, there are many recommender system techniques applied in the industry. Some resources stated several broad categories are content-based, collaborative filtering, and knowledgebased [11]. Every type has its content-based characteristics refers to user preferences for objects that are predicted from the transaction history. Moreover, collaborative filtering utilized user preferences for objects that are deemed similar, and knowledge-based usually maintaining a knowledge base of user profiles. In this study, we use a content-based that has feasible computational requirements and is tailored to the goal of providing learning partner recommendations. The recommender system is real-time to provide recommendations on the spot when the user already has set up the parameter needed, such as course topic, job information, learning partners competency, etc. Some recommender system research in the higher education system focuses to enhance the learning process that can be seen in Table 1 . 


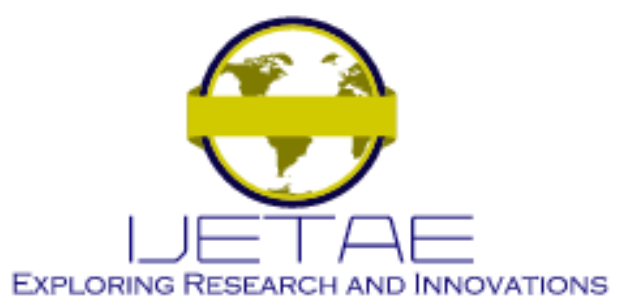

International Journal of Emerging Technology and Advanced Engineering

Website: www.ijetae.com (E-ISSN 2250-2459, Scopus Indexed, ISO 9001:2008 Certified Journal, Volume 11, Issue 06, June 2021)

Tabel 1

Recommender System Research

\begin{tabular}{|l|l|l|}
\hline \multicolumn{1}{|c|}{ Method } & \multicolumn{1}{c|}{$\begin{array}{c}\text { Context } \\
\text { Functionality }\end{array}$} & References \\
\hline $\begin{array}{l}\text { Collaborative } \\
\text { filtering }\end{array}$ & $\begin{array}{l}\text { e-learning } \\
\text { recommender } \\
\text { systems }\end{array}$ & {$[12][13][14]$} \\
\hline $\begin{array}{l}\text { Deep learning } \\
\text { hybrid } \\
\text { recommender } \\
\text { system }\end{array}$ & General & {$[15][16]$} \\
\hline Social Analytics & $\begin{array}{l}\text { Online learning } \\
\text { communities }\end{array}$ & {$[17][18][19]$} \\
\hline Meta-Learning & e-learning & {$[20][21]$} \\
\hline
\end{tabular}

Most of the previous research focused to define the subject course that might be student preferences because the system read the historical data from the user learner, but there is not specifically research that use this method to identify learning partner. Therefore, this research will focus on building an interactive recommender system as the tool to support learning partner selection to build an interactive learning process.

\subsection{Social Media}

Currently, the use of social media is widespread and initiates new opportunities in many business sector organizations to interact with the customer, student, patients, policymakers, public, and each other [22]. The global interest of users to use social media portals has reinforced much research that focuses to discover knowledge from the publicly available [23]. Social media offers the possibility of facilitating users with up-to-date information where, when, and how they want it, but this fact also brings with it some challenge to the organization. With the proliferation use of social media, there is potential innovation to change the way the organization operates. However, every higher education institution needs to be aware of current trends. An organization requires an application to achieve the desired outcome. Moreover, it needs to be monitored to manage the reliability, accuracy, quality, confidentiality, the privacy of the data.
Most importantly, social media today becomes more sophisticated and widely adopted in higher education institutions [24]. LinkedIn has become a key social media for rapidly disseminating user profiles to promote to the company. Many people join this LinkedIn to record their professional profiles. Most organizations use LinkedIn as a place to find the candidate of the employee to join. Therefore, this study focuses to use this social media because it can be a mediating platform to identify learning partners that suitable for the requirement from learning topic in a higher education institution.

\subsection{Social Learning}

Most people spend their daily lives socially interacting and connecting with others. Moreover, this condition drives the process of learning and facilitating knowledge acquisition from the surrounding environment and other influences [25]. Social learning is an important approach used widely by an individual to absorb skills from others. Accordingly, this concept stated that the learning process is generated from observation of, or interaction with through social learning, the competency of one individual is empowered by another individual. The process of social learning transmission can occur in a different approach. The success of social learning depends upon both the quality and quantity of the learning opportunities and the support system that can mediate the process of learning. In the higher education institution learning process can be initiate from every interaction from every personnel that interacts in the learning process. An increase in the quantity of social learning will impact the knowledge of the student and lead to more social. This condition can be achieved by enlarging the number of social learning models in the institution [26]. The recommendation system has emerged as an important tool to assist users in deciding based on some criteria and preferences. This potential system is still rarely utilized in social learning to help in an area that could assist both university, student, and learning partner collaboration. Therefore, this study purpose to fulfill this requirement that integrates with the recommender system to select learning partners from the external parties that can contribute to enhancing the social learning process. 


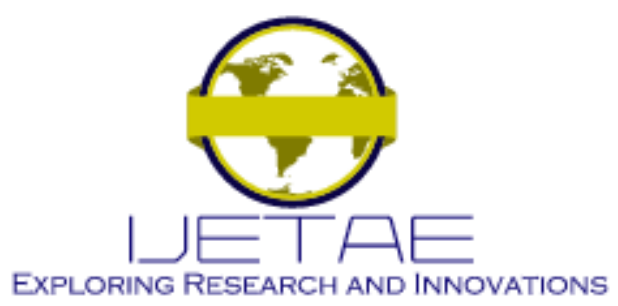

International Journal of Emerging Technology and Advanced Engineering

Website: www.ijetae.com (E-ISSN 2250-2459, Scopus Indexed, ISO 9001:2008 Certified Journal, Volume 11, Issue 06, June 2021)

\section{Methodology}

Ontology is the core of this study model, which contain information about learning topic, learning partner competency, mapping between learning topic with the future job, and exploring the candidate of a learning partner. The methodology as a foundation of this study adopts from design science research because this method inherently a problem-solving process that suitable for higher education institution problem. The stage methodology of this study consists of design as an artifact of interactive recommender, problem relevance of the recommender system, design evaluation, research contributions, research rigor, design as a search process, and communication of research [27]. The recommendation process performed by a recommender system that follows some steps: learning topic specification, preference acquisition based on higher education expectation of future job, profile building from learning partner in the LinkedIn social media, exploring learning partner competency, generation of a list of recommendation, and user evaluation and confirmation of the recommendation. It is important for organizations to get to know that the components and the recommendation steps are not the same things, the former stated that different moments in the user recommender interaction [28].

The implementation of a recommender system consisting of two phases, which are the formulation phase and recommender phase. In the formulation phase, raw data from the learning material and certain requirement features are analysed as input and output of the recommender system. The creation algorithm will be made in the recommender phase to apply the proposed method [29]. This phase will be calculated and tested the possibility can be obtained through the calculation based on the learning partner mapping. The phase of recommender systems is shown in Fig. 1 below.

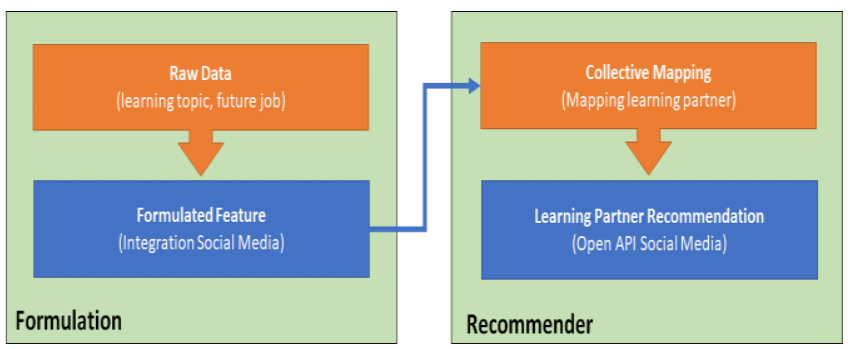

Figure 1 Stages of Recommender System
The set of possible design solutions for any concern is specified as all possible means that satisfy all conditions based on job information stated in the course outline. As a guideline to explore a suitable learning partner. When these can be formulated appropriately, this study defined standard operations for an application that can be used to determine an optimal solution for the specified end conditions in the higher education process.

\section{REsUlt}

The result focuses on artifact interactive recommender constructed in design science research that is used for a higher education institution. Instead, artifacts are an innovation that defines the ideas for recommender system, this design refers to some input from the user perspective by decomposing a problem into a subproblem. Such decomposition is made interactively as the scope of the design problem from the higher education institution that difficult to find out the right learning partner.

The main component of the proposed interactive recommender systems is the design of knowledge for learning material, which is created using the ontological model. Ontologies are considered powerful tools to support formalizing and modelling various knowledge-based systems [30]. Most ontological models involve the classification of learning topic material related to a future job description that suitable for learning partner competency. We can easily generate propose learning partner from previous mapping results. In Fig 2, we can see the flow ontological model of interactive recommender systems. The ontological proposed system will combine learning management systems, core services, and social media LinkedIn functionality. Learning Management Systems (LMS) as the learning backbone system will accommodate teaching activity that involves lectures and students, the core process in the learning management systems consist of creating learning materials, manage forum discussion, manage learning schedule, manage assignment/quiz/exam, message/chat with the student, grading. These activities execute internally in higher education learning systems and can be accessed by all participants in the learning process. To connect with a learning partner in LinkedIn, first-time institutions have to map course material with future job information that suitable for the learning outcome. 


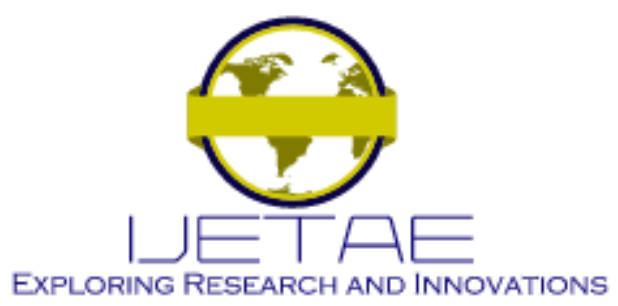

International Journal of Emerging Technology and Advanced Engineering

Website: www.ijetae.com (E-ISSN 2250-2459, Scopus Indexed, ISO 9001:2008 Certified Journal, Volume 11, Issue 06, June 2021)

The map will be used by the core process to explore learning partners in the LinkedIn social media based on keyword future job that will explore from people, posts, jobs, groups, companies, schools, events, courses that comply with the requirement based on the qualification in the job mapping. All the process maps will be executed by the core process that consists of dialog manager and recommendation services.

After LinkedIn generates the learning partner's recommendation, then the system will ask the user from higher education institution to give confirmation, which candidate will be processed. If the institution has chosen the candidate, then the system will send an email invitation to the LinkedIn account of the candidate. If the candidate agrees to be involved, then they can reply to the email to approve this request, then they will get access to enter learning management systems according to the topic that has been mapped before. The learning partner can join into the learning process as an instructor, then they can share additional material, discuss in the forum, share assignment/project, and give feedback to the student. The interaction between the learning partner and the student will be monitored and guided by a lecturer in the class as the moderator that makes sure the learning process can be more conducive and interactive because the learning partner joins on learning activities. Students can discuss with learnings partner according to of learning topic and the correlation in the real working life, so the student can open their mindset to prepare their competency that can meet industry expectation in the future. The interaction between learning management systems, core services, and social media LinkedIn can be seen in Fig. 2

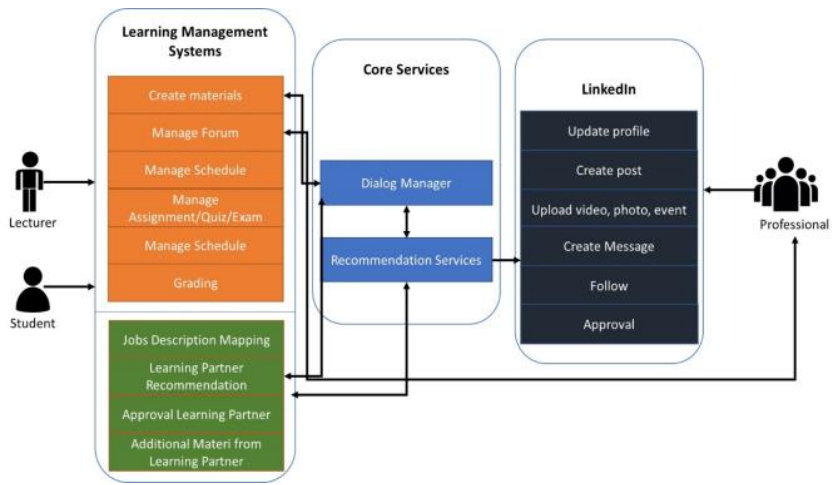

Figure 2 Ontological Model of Interactive Recommender Systems
After this study builds the ontological model as the backbone of interactive recommender systems, then next process, this study builds the system solution that represents how the systems work to integrate recommender systems in this study. The learning process runs as usual in the higher education institution that accommodates from learning management system which provides some learning activity process. The below description will highlight how recommender systems work to combine learning management systems platform and LinkedIn as social media that can support seeking learning partner. Fig 3 shows the Learning Management System that has embedded to find learning partner based on the mapping from job information in the course mapping. This process will connect to LinkedIn API as media to meet professionals from an external institution. The process to connect with the LinkedIn will mediated using JSON response that will parse the parameters to the user learning management system.

The process to find out an appropriate candidate learning partner that have suitable competency and qualifications can be defined as follows:

\section{Searching process}

This process will generate LinkedIn data, such as name, job, first name, last name, job location, etc) into LMS database. Fig 3. shows that the profile user's data that will generated.

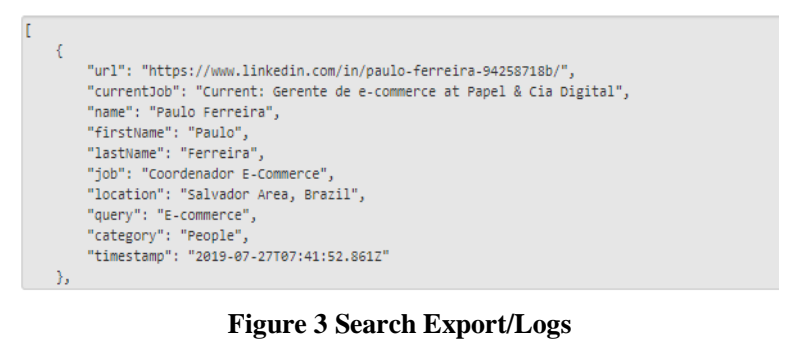

\section{LinkedIn Profile Scraper}

LinkedIn profile scraper has functionality to capture LinkedIn profile URL's data as object and generate user profile data from LinkedIn. The detail data that will be processed are: 


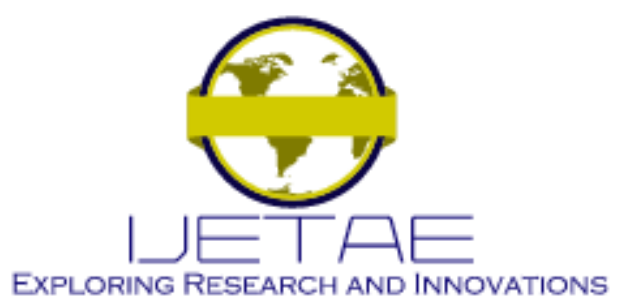

International Journal of Emerging Technology and Advanced Engineering Website: www.ijetae.com (E-ISSN 2250-2459, Scopus Indexed, ISO 9001:2008 Certified Journal, Volume 11, Issue 06, June 2021)

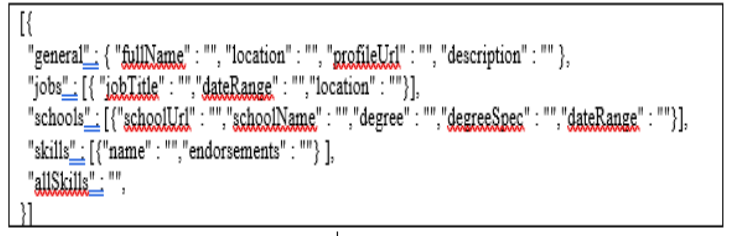

Figure 4 Profile Scrapper

The proposed of mechanism recommender system can be run using learning management system that already implemented in the higher education institution. In this study use the social learning systems that already built in the previous study [31] [32]. The learning management system will be integrated with the social media LinkedIn as single sign on of the learning management side. After the user already selected the candidate criteria. The data will be saved as lecturer qualification profile.

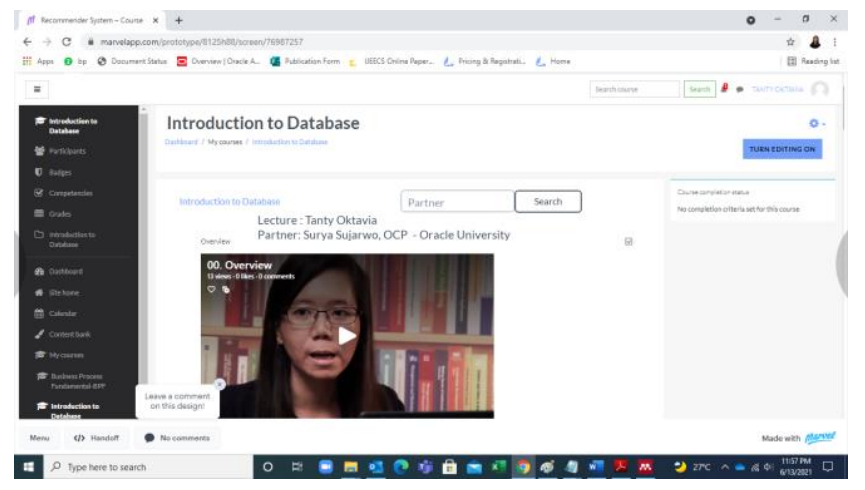

Figure 3 Searching Process.

After the LMS connect with LinkedIn API, then LinkedIn will show list candidate based on the keyword job information in the course mapping. The output can be shown in Fig. 4. Higher education institution has to choose candidate will be proposed to be learning partner that suitable with the topic. The learning partner has to meet the criteria based on their competency, experience, and qualification. Then, after the candidate is selected, the system sends the request for approval to the candidate (Fig. $5)$.

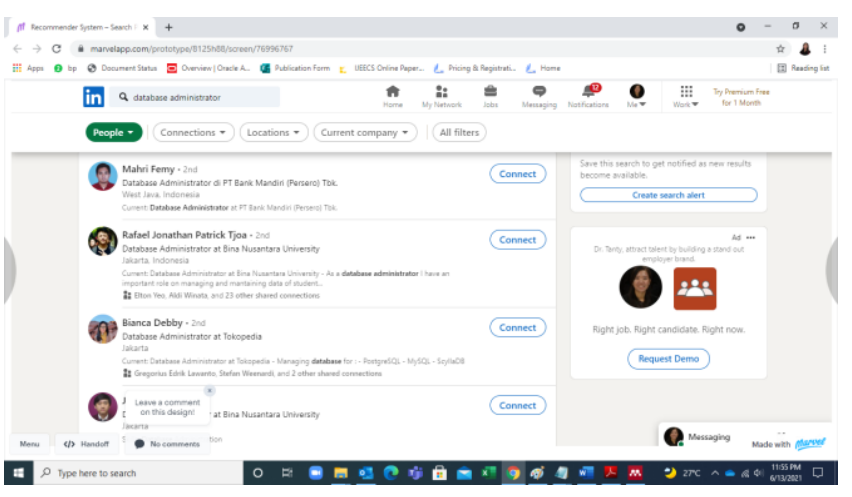

Figure 5 List Candidate

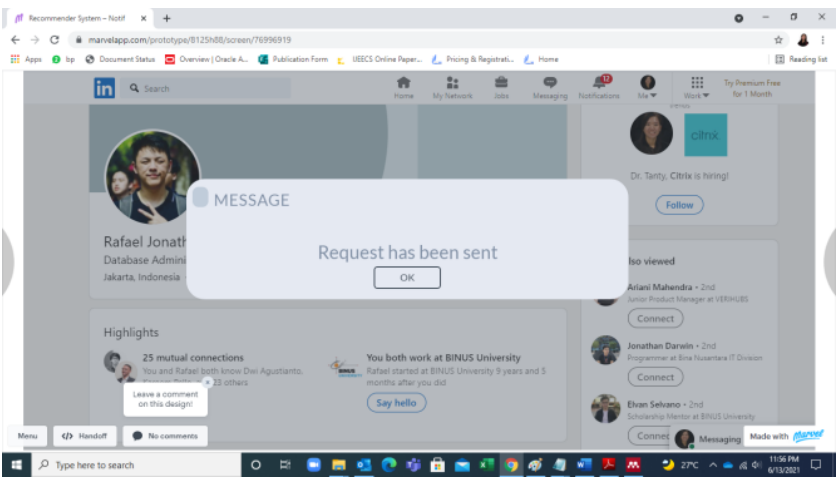

Figure 5 Request

In the learning partners account, the LinkedIn account will notify request from the sender. The candidate can read the message content that shows the background and detailed invitation from a sender that comes from higher education institution (Fig 6) and he/she can respond to the invitation using the LinkedIn platform as an intermediary of this process.

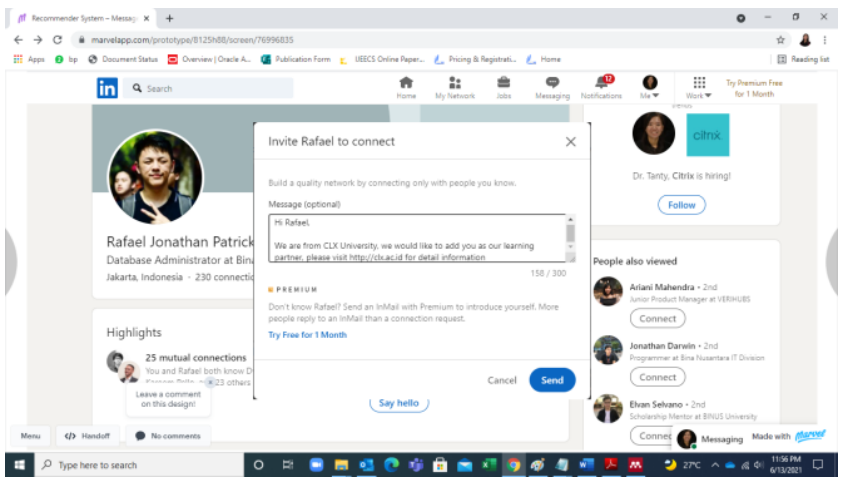

Figure 6 Confirmation 


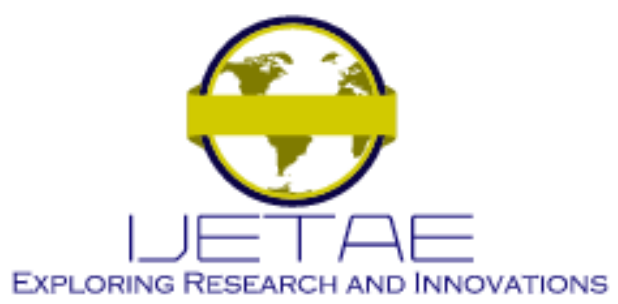

International Journal of Emerging Technology and Advanced Engineering

Website: www.ijetae.com (E-ISSN 2250-2459, Scopus Indexed, ISO 9001:2008 Certified Journal, Volume 11, Issue 06, June 2021)

If the candidates agree to join (Fig 7), they can reply to the message to the institution or if they need some clarification, they can reply using the message to the sender.

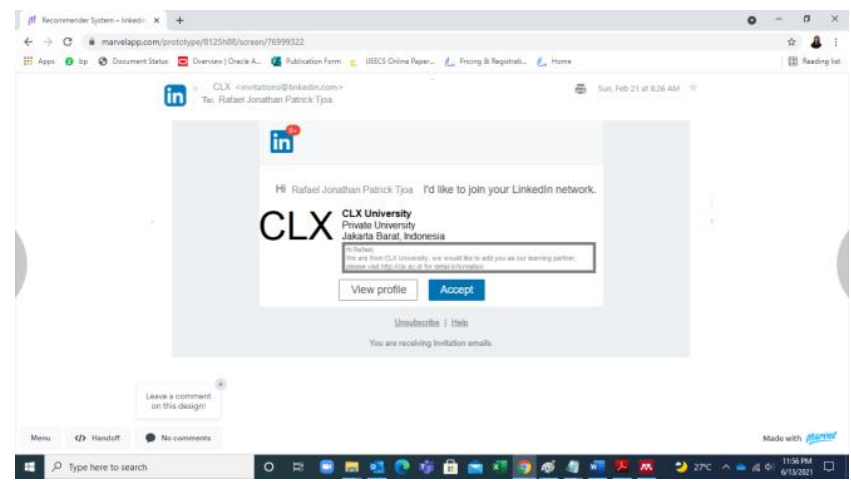

Figure 7 Approval

After the approval process, the learning partner will get access to the learning management system. Learning partners can interact in the forum discussion and they also can share additional material needed. All the activity directly processes in the learning management systems to support collaboration between learning partners and internal parties. Learning partners also can communicate with all students and lectures on the topic of material that already set up before. Fig 8 shows the discussion forum activity that involves a learning partner.

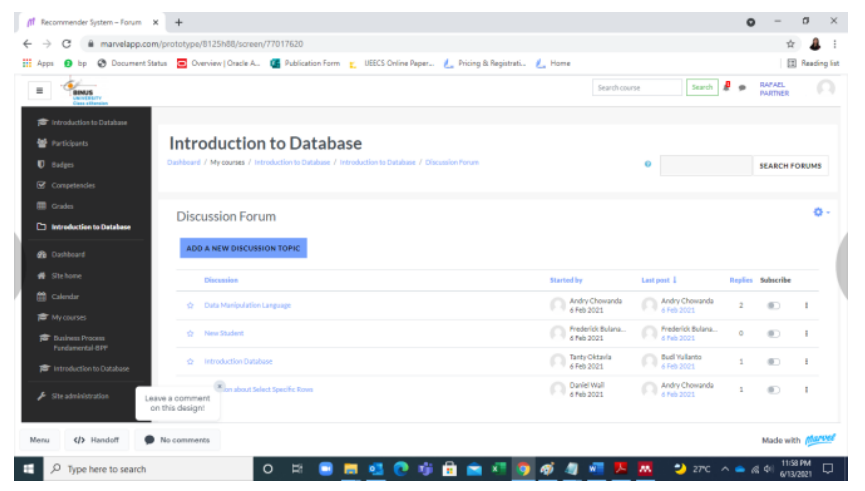

Figure 8 Discussion forum

With these interactive recommender systems, all the higher education needs to collaborate with the learning partner can be realized easily and suitable with the learning outcomes. So, most of the problem about the graduate's gap can be minimized if the higher education implements this system and open their learning process mindset.
The existing systems do not have mapping into learning outcome from subject materials, but they only seek the learning partner based on expertise. This study result will validate based on learning outcome per topic subject materials that map into learning partners that have an appropriate qualifications according to LinkedIn profile [33] [34].

\section{CONCLUSION}

Rapidly technology today brings advantages in many aspects of life. Accordingly, recommender systems that predict the possible correlation between user and object can solve problems and reduce the operational cost to search the proper data. As a result, recommender systems have increasingly become a popular technology in the organization to increase their performance. This shifting also happens in the higher education institution, as a place that always innovates to bring the best experience for the students. In this study, we explore several feasible candidates' recommender systems to identify learning partners and how to match learning partners with topic material. In the traditional approach, all data must be collected in advance [28] and recommender systems produce referrals to organizations to satisfy their objective to the extent reflecting their interests and preferences [35]. Therefore, this study focuses to empower recommender system functionality that is believed can help universities to organize their operational more excellent. Accordingly, this study proposes a novel solution that can find an appropriate learning partner to collaborate in the learning process. This system works by matching the subject's course with learning partner competency using an interactive recommender application that connects with social media LinkedIn. With this system, the university does not difficult to search for learning partners that comply with their qualifications based on alignment between learning topic and partner competency. The proposed system can be integrated with a learning management system from every university, so they can find learning partners based on parameters from their learning material. This system could reveal a new concept of the learning process in higher education and outline future research directions to identify the best method of recommender systems in term of speed, accuracy, interactive, etc. compare with other recommender approaches, so this system could be more powerful as learning partner recommender systems. 


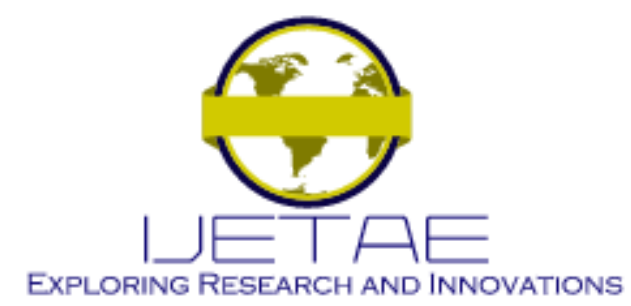

International Journal of Emerging Technology and Advanced Engineering

Website: www.ijetae.com (E-ISSN 2250-2459, Scopus Indexed, ISO 9001:2008 Certified Journal, Volume 11, Issue 06, June 2021)

\section{Acknowledgement}

This work is supported by Directorate General of Research and Development Strengthening, Indonesian Ministry of Research, Technology, and Higher Education, as a part of Penelitian Dasar Unggulan Perguruan Tinggi Research Grant to Binus University titled "Pengembangan Sistem Rekomendasi Pakar Sebagai Penunjang Proses Pembelajaran Pada Tingkat Perguruan Tinggi" with contract number: 225/SP2H/LT/DRPM/2019; 12/AKM/PNT/2019; 039/VR.RTT/IV/2019 and contract date: 27 March 2019.

\section{REFERENCES}

[1] Z. K. A. Baizal, D. H. Widyantoro, and N. U. Maulidevi, "Computational model for generating interactions in conversational recommender system based on product functional requirements," Data Knowl. Eng., vol. 128, no. March, p. 101813, 2020, doi: 10.1016/j.datak.2020.101813.

[2] R. Barzegar Nozari and H. Koohi, "A novel group recommender system based on members' influence and leader impact," Knowledge-Based Syst., vol. 205, p. 106296, 2020, doi: 10.1016/j.knosys.2020.106296.

[3] S. Gupta and V. Kant, "Credibility score based multi-criteria recommender system," Knowledge-Based Syst., vol. 196, no. xxxx, p. 105756, 2020, doi: 10.1016/j.knosys.2020.105756.

[4] B. Walek and V. Fojtik, "A hybrid recommender system for recommending relevant movies using an expert system," Expert Syst. Appl., vol. 158, p. 113452, 2020, doi: 10.1016/j.eswa.2020.113452.

[5] G. Nápoles, I. Grau, and Y. Salgueiro, "Recommender system using Long-term Cognitive Networks,' Knowledge-Based Syst., vol. 206, p. 106372, 2020, doi: 10.1016/j.knosys.2020.106372.

[6] F. Cena, L. Console, and F. Vernero, "Logical foundations of knowledge-based recommender systems: A unifying spectrum of alternatives," Inf. Sci. (Ny)., vol. 546, pp. 60-73, 2021, doi: 10.1016/j.ins.2020.07.075.

[7] V. Kumar and S. Shrivastva, Krishna Mohan PD, Singh, "Cross Domain Recommendation Using Semantic Similarity and Tensor Decomposition,” Procedia Comput. Sci., vol. 85, 2016.

[8] Q. E. Booker, "a Student Program Recommendation System Prototype," Issues Inf. Syst., vol. X, no. 2, 2009, doi: 10.48009/2_iis_2009_544-551.

[9] I. Mazeh and E. Shmueli, "A personal data store approach for recommender systems: enhancing privacy without sacrificing accuracy," Expert Syst. Appl., vol. 139, 2020, doi: 10.1016/j.eswa.2019.112858.

[10] J. Herce-Zelaya, C. Porcel, J. Bernabé-Moreno, A. Tejeda-Lorente, and E. Herrera-Viedma, "New technique to alleviate the cold start problem in recommender systems using information from social media and random decision forests," Inf. Sci. (Ny)., vol. 536, pp. 156-170, 2020, doi: 10.1016/j.ins.2020.05.071.
[11] M. Suleiman, H. Demirhan, L. Boyd, F. Girosi, and V. Aksakalli, "A clinical coding recommender system," Knowledge-Based Syst., vol. 210, p. 106455, 2020, doi: 10.1016/j.knosys.2020.106455.

[12] J. Bobadilla, F. Serradilla, and A. Hernando, "Collaborative filtering adapted to recommender systems of e-learning," Knowledge-Based Syst., vol. 22, no. 4, pp. 261-265, 2009, doi: 10.1016/j.knosys.2009.01.008.

[13] J. Monsalve-Pulido, J. Aguilar, E. Montoya, and C. Salazar, "Autonomous recommender system architecture for virtual learning environments," Appl. Comput. Informatics, no. $\mathrm{xxxx}$, pp. 1-11, 2020, doi: 10.1016/j.aci.2020.03.001.

[14] M. Elahi, F. Ricci, and N. Rubens, "A survey of active learning in collaborative filtering recommender systems," Comput. Sci. Rev., vol. 20, pp. 29-50, 2016, doi: 10.1016/j.cosrev.2016.05.002.

[15] K. R, P. Kumar, and B. Bhasker, "DNNRec: A novel deep learning based hybrid recommender system," Expert Syst. Appl., vol. 144, p. 113054, 2020, doi: 10.1016/j.eswa.2019.113054.

[16] J. sheng Guan, M. Xu, and X. song Kong, "Learning social regularized user representation in recommender system," Signal Processing, vol. 144, pp. 306-310, 2018, doi: 10.1016/j.sigpro.2017.09.015.

[17] Y. Li, H. Bao, Y. Zheng, and Z. Huang, "Social Analytics Framework to Boost Recommendation in Online Learning Communities," 2015, doi: 10.1109/ICALT.2015.100.

[18] I. Mashal, O. Alsaryrah, and T. Y. Chung, "A multi-criteria analysis for an internet of things application recommendation system," Technol. Soc., vol. 60, no. November 2018, p. 101216, 2020, doi: 10.1016/j.techsoc.2019.101216.

[19] H. Alharbi and P. Kwan, "Social recommender system for predicting the needs of students/instructors: Review and Proposed Framework," in 2014 International Conference on Future Internet of Things and Cloud, 2014, pp. 534-540, doi: 10.1109/FiCloud.2014.93.

[20] R. G. Mantovani, A. L. D. Rossi, E. Alcobaça, J. Vanschoren, and A. C. P. L. F. de Carvalho, "A meta-learning recommender system for hyperparameter tuning: Predicting when tuning improves SVM classifiers," Inf. Sci. (Ny)., vol. 501, pp. 193-221, 2019, doi: 10.1016/j.ins.2019.06.005.

[21] A. H. Afridi, "Visualizing serendipitous recommendations in user controlled recommender system for learning," Procedia Comput. Sci., vol. 141, pp. 496-502, 2018, doi: 10.1016/j.procs.2018.10.136.

[22] L. Esmaeili, S. Mardani, S. A. H. Golpayegani, and Z. Z. Madar, “A novel tourism recommender system in the context of social commerce," Expert Syst. Appl., vol. 149, p. 113301, 2020, doi: 10.1016/j.eswa.2020.113301.

[23] D. K. Jain, A. Kumar, and V. Sharma, "Tweet recommender model using adaptive neuro-fuzzy inference system," Futur. Gener. Comput. Syst., vol. 112, pp. 996-1009, 2020, doi: 10.1016/j.future.2020.04.001.

[24] D. Patel and D. Jermacane, "Social media in travel medicine: A review," Travel Med. Infect. Dis., vol. 13, no. 2, pp. 135-142, 2015, doi: 10.1016/j.tmaid.2015.03.006.

[25] B. Lindström, J. Haaker, and A. Olsson, "A common neural network differentially mediates direct and social fear learning," Neuroimage, 2017, doi: 10.1016/j.neuroimage.2017.11.039. 


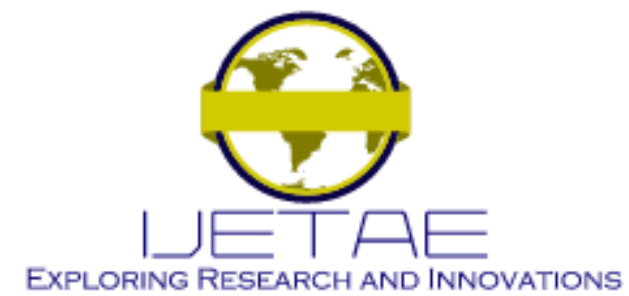

International Journal of Emerging Technology and Advanced Engineering Website: www.ijetae.com (E-ISSN 2250-2459, Scopus Indexed, ISO 9001:2008 Certified Journal, Volume 11, Issue 06, June 2021)

[26] B. van Boekholt, E. van de Waal, and E. H. M. Sterck, "Organized to learn: the influence of social structure on social learning opportunities in a group," iScience, vol. 24, no. 2, p. 102117, 2021, doi: 10.1016/j.isci.2021.102117.

[27] A. Hevner and S. Chatterjee, Design Research in Information Systems. USA, 2010.

[28] A. Iovine, F. Narducci, and G. Semeraro, "Conversational Recommender Systems and natural language:: A study through the ConveRSE framework," Decis. Support Syst., vol. 131, no. January, 2020, doi: 10.1016/j.dss.2020.113250.

[29] J. Zheng, C. S. Lai, H. Yuan, Z. Y. Dong, K. Meng, and L. L. Lai, "Electricity plan recommender system with electrical instructionbased recovery," Energy, vol. 203, p. 117775, 2020, doi: 10.1016/j.energy.2020.117775.

[30] M. Dong, X. Zeng, L. Koehl, and J. Zhang, "An interactive knowledge-based recommender system for fashion product design in the big data environment," Inf. Sci. (Ny)., vol. 540, pp. 469-488, 2020, doi: 10.1016/j.ins.2020.05.094.
[31] T. Oktavia, Meyliana, S. H. Supangkat, and H. Prabowo, "Social Media as a New Channel Learning For Higher Education ( A Survey Approach )," in 2016 International Conference on ICT For Smart Society, 2016, no. July, pp. 20-21.

[32] T. Oktavia, A. N. Hidayanto, Meyliana, S. H. Supangkat, and H. Prabowo, "Infusing functionality of social media as a transformative higher education teaching and learning process into social learning system,” Int. J. Innov. Learn., vol. X, 2019.

[33] C.-Y. Yao, C.-C. Tsai, and Y.-C. Fang, "Understanding social capital, team learning, members' e-loyalty and knowledge sharing in virtual communities," Total Qual. Manag. Bus. Excell., vol. 3363, no. July 2015, pp. 1-13, 2014, doi: 10.1080/14783363.2013.865918.

[34] J. J. Bos, R. R. Brown, and M. A. Farrelly, "A design framework for creating social learning situations," Glob. Environ. Chang., vol. 23, no. 2, pp. 398-412, 2013, doi: 10.1016/j.gloenvcha.2012.12.003.

[35] E. Yalcin, F. Ismailoglu, and A. Bilge, "An entropy empowered hybridized aggregation technique for group recommender systems," Expert Syst. Appl., vol. 166, no. September 2020, p. 114111, 2021, doi: 10.1016/j.eswa.2020.114111. 